\title{
Métrica, tropos y figuras en las Anotaciones de Fernando de Herrera
}

\author{
Metre, Tropes, and Figures \\ in Fernando de Herrera's Anotaciones
}

\author{
Esteban Torre \\ Universidad de Sevilla
}

\section{RESUMEN}

En el año 1580, se publicaron por primera vez en Sevilla las Obras de Garcilaso de la Vega con anotaciones de Fernando de Herrera, que edita y comenta treinta y cinco sonetos, cinco canciones, dos elegías, una epístola y tres églogas del poeta toledano. Con excepción de la epístola, cada una de las otras formas poemáticas va seguida de una extensa disertación de corte fundamentalmente histórico y erudito. Pero lo más interesante son los comentarios puntuales que hace a determinados versos, que nos revelan a un profundo conocedor de las teorías poéticas vigentes en la segunda mitad del siglo XVI y a un crítico literario extraordinariamente perspicaz y sensible. Se reúnen, analizan y sistematizan aquí sus numerosísimas referencias a las cuestiones métricas y al lenguaje tropológico y figurado.

Palabras Clave: Fernando de Herrera; Garcilaso de la Vega; métrica; tropos; figuras; teoría literaria; crítica literaria.

\begin{abstract}
In the year 1580 in Seville, the Works of Garcilaso de la Vega with Annotations by Fernando de Herrera were first published, in which he edits and comments on thirty-five sonnets, five songs, two elegies, one letter, and three eclogues by the Toledo-born poet. With the exception of the letter, each of the other poetic formats is followed by an extensive dissertation of a largely historical and scholarly kind. Yet, what is of greatest interest are the specific comments he makes upon concrete lines of verse, comments which reveal him as possessing a thorough knowledge of the poetic theories in vogue during the second half of the sixteenth century, and also as an extraordinarily perceptive and sensitive literary critic. In this discussion his numerous references to metrical-based issues, as well as to tropological and figurative language, are mulled over, analyzed, and systematized.
\end{abstract}

Key words: Fernando de Herrera; Garcilaso de la Vega; Metre; Tropes; Figures; Literary Theory; Literary Criticism. 
Se ha venido repitiendo y poniendo énfasis en la importancia de Fernando de Herrera como «el primer crítico literario español», según ha escrito recientemente Rocío Badía (2013), quien aduce como citas de autoridad algunos trabajos de Oreste Macrì (1972), José Almeida (1976) y Manuel Ángel Vázquez (1983), además de hacerse eco de la opinión mayoritaria de Antonio Vilanova (1953), para quien las Obras de Garcilaso de la Vega con anotaciones de Fernando de Herrera (1580) constituirían «la más importante arte poética española del siglo XVI», junto a la Filosofía antigua poética de Alonso López Pinciano. En este mismo sentido, Pedro Piñero (2002) hace constar que el crítico y poeta sevillano habría conseguido formular con sus Anotaciones «la primera gran poética de la historia de la literatura española» ${ }^{1}$.

A decir verdad, ya a finales del siglo XIX, Marcelino Menéndez Pelayo (1974: 733-735), en su Historia de las ideas estéticas en España, había hecho ver la importancia de las Anotaciones de Fernando de Herrera, en competencia con las notas del Brocense, aparecidas seis años antes. Constituirían dichas Anotaciones «una cabal arte poética», elaborada a partir de los amplios conocimientos de los clásicos y de los italianos, así como de sus propias experiencias. Según Menéndez Pelayo, Herrera reunía todas las condiciones del auténtico humanista y hombre de letras: «era un gran crítico, un idólatra de la forma». En contraste con las notas eruditas, exegéticas, centradas en el estudio de las fuentes, de Francisco Sánchez de las Brozas (1600; primera edición de 1574), las de Fernando de Herrera constituyen «un verdadero curso de teoría literaria» y su autor se nos revela como «el primero de nuestros críticos del siglo XVI» ${ }^{2}$. Con objeto de matizar y sopesar estas aseveraciones, el presente trabajo ofrece una atenta lectura de las Anotaciones, muy próxima al texto, en la que se ponen de relieve los conceptos y los términos utilizados por Herrera, referentes a la métrica y a la teoría del lenguaje figurado y tropológico.

De la edición de las Anotaciones de 1580, existen decenas de ejemplares, en España y fuera de España, y concretamente, en Sevilla — ciudad natal del teórico, crítico y poeta-, dos en la Biblioteca General de la Universidad de Sevilla (Signs. Res 11-5-11 y Res 21-3-19), y uno en la Biblioteca Capitular y Colombina (Sign. 88-5-10). Recuerdo la emoción que me produjo en su día

${ }^{1}$ Vid. una amplia bibliografía sobre Fernando de Herrera y sus Comentarios en Martínez Ruiz (1997: 286-296).

${ }^{2}$ Advierte Juan Montero (1997: 92) que «Herrera se olvida momentáneamente de su labor de editor para poner todo el énfasis en realizar la de comentarista y crítico de los versos garcilasianos», poniendo así de manifiesto que sus planteamientos «son bastante distintos de los que habían animado al Brocense». En esta misma línea, Valentín Núñez Rivera (1997: 116) hace ver cómo Fernando de Herrera, «a pesar de tener en cuenta en todo momento para su trabajo la edición de 1574, no nombra ni una sola vez al Brocense». En todo caso, en opinión de Ángel Estévez Molinero (1997: 133), «Herrera es consciente de que su modo de anotar es novedoso». 
tener entre mis manos un ejemplar de la edición princeps de las Anotaciones en la comúnmente conocida como Biblioteca del Rectorado, con motivo de una exhaustiva consulta de sus fondos antiguos para el estudio del pensamiento español en torno a la lengua y la literatura en la segunda mitad del siglo XVI (Torre, 1984). En lo que concierne a la relación entre las palabras y las cosas, junto al parecer del licenciado Pedro de Guevara (1586: 14), para quien «de quanto se puede tratar, o son cosas, o conceptos, o vozes», o del doctor Juan Sánchez Valdés de la Plata (1598: 140), que indica que la lengua es «intérprete y mensagera del entendimiento», resplandecían las anotaciones de Fernando de Herrera al Soneto XI de Garcilaso, en las que se afirma que «las palabras son imágenes de los pensamientos» $\mathrm{y}$, precisamente por eso, conviene que sean claras, llanas, enteras. Cierto es que, muchas veces, hay oscuridad en las cosas, pero «no deve oscurecerse más con las palabras, porque basta la dificultad de las cosas» (Herrera, 1580: 126).

Desde 1973, disponemos de una edición facsimilar, inicialmente preparada por Alfredo Carballo, y prologada finalmente por Antonio Gallego Morell (1973), quien con anterioridad había publicado un importante trabajo sobre Garcilaso de la Vega y sus comentaristas (1972). Una segunda edición facsímil, con estudio biobibliográfico, fue publicada en 1998 por Juan Montero. En 2001, aparece la edición de Inoria Pepe Sarno y José María Reyes Cano, con un aparato crítico insuperable, que incluye variantes, problemas textuales, fuentes, fundamentos teóricos y todo tipo de datos históricos y referencias mitológicas. La lectura está facilitada por la modernización de los moldes de imprenta, la puntuación y los signos diacríticos. Se harán todas las citas teniendo en cuenta el texto de esta edición, señalando el poema concernido y, en su caso, la línea del verso correspondiente al comentario herreriano.

Dedica Fernando de Herrera a cada uno de los géneros poéticos de Garcilaso, tras el Soneto I, la Canción I, la Elegía I y la Égloga I, una extensa parrafada o «discurso», en donde se definen y comentan las respectivas características de dichos géneros. Por lo que respecta a las formas estróficas, menciona el terceto, el terceto encadenado, el cuartel (cuarteto) y la octava real.

El soneto es «la más hermosa composición i de mayor artificio y gracia de cuantas tiene la poesía italiana i española». En ningún otro género se requiere más cuidado y pulcritud, ya que en él no se admite el menor error ni una sola palabra que sea «ociosa o vana». El tema ha de ser expuesto de una manera clara y sencilla, «huyendo la oscuridad i dureza»:

...y la brevedad suya no sufre, que sea ociosa, o vana una palabra sola. I por esta causa su verdadero sugeto i materia deve ser principalmente alguna sentencia ingeniosa i aguda, o grave, i que meresca bien ocupar aquel lugar todo; descrita de suerte que paresca propria i nacida en aquella parte, huyendo la oscuridad i dureza.

En realidad, estas palabras de Fernando de Herrera no son más que una mera traducción literal de un texto de Lorenzo de' Medici (1449-1492): 
La brevità del sonetto non comporta, che una sola parola sia vana, ed il vero subietto e materia de' sonetti per questa ragione debbe essere qualche acuta, e gentile sentenza, narrata attamente, ed in pochi versi ristretta, fuggendo la oscurità e durezza (Lorenzo de' Medici: 1991, 150).

La correspondencia textual fue ya puesta de manifiesto por Gary Joseph Brown (1975: 233), quien hizo ver que la fuente directa de Herrera, por lo que respecta a sus ideas sobre el soneto, reside en el Comento de Lorenzo de' Medici. Una reseña en las páginas 375-376 de la Revista de Filología Española (vol. LX, $\mathrm{n}^{\circ} 1 / 4,1978-80$ ) dio oportuna noticia de este importante hallazgo, indicando cómo, en cualquier caso, «termina diciendo Brown, es Herrera el más lúcido y original de todos los preceptistas españoles del Siglo de Oro». En efecto, concluye Brown (1975: 238) que, a pesar de que autores contemporáneos, como el Prete Jacopín ${ }^{4}$, o investigadores recientes, como Adolphe Coster (1908), Robert Mills Beach (1908) o Robert Pring-Mill (1967), hayan podido criticar su plagiarism, las observaciones de Herrera sobre el soneto demuestran un profundo conocimiento que dimana inicialmente de su propia experiencia ${ }^{5}$.

El favorable juicio de Brown no fue obstáculo para que algún tratadista (Lázaro Carreter, 1980: 315-321) presentara, cinco años después, los citados textos como algo novedoso, que vendría a revelarnos la «sumisión» de Fernando de Herrera al pasaje de Lorenzo de' Medici y su reprobable «proceder moral» (1980: 319), poniéndose así en evidencia «el verdadero perfil deontológico de Herrera como artista» y su «dudoso valor ético» (1980: 321). Hasta su misma prosa es conceptuada mordazmente como «el castellano del andaluz». En consecuencia, la opinión de Menéndez Pelayo, según la cual las Anotaciones constituirían una lograda arte poética, asentada sobre su profundo conocimiento de los clásicos y de los italianos, y sobre sus propias experiencias, sería un juicio elaborado «con sensible rapidez» (1980: 315).

La cuestión de la copia o el plagio en las Anotaciones ha de ser considerada, en cualquier caso, desde una perspectiva histórica. Como señala Ángel Luis Luján (2000: 359), «la técnica de la copia era habitual y nada escandalosa en la época». Bienvenido Morros (1997: 37-89), que ha dedicado un extenso y bien documentado artículo a las fuentes de las Anotaciones, hace ver cómo Herrera traduce unas veces al pie de la letra y otras se aparta del texto

\footnotetext{
${ }^{3}$ La primera edición del Comento de los sonetos de Lorenzo de' Medici data de 1554, realizada en Venecia por los hijos de Aldo Manucio, como añadido a una nueva edición de la Poesie volgari del «Magnífico». Existen manuscritos en distintas instituciones, entre ellas la Biblioteca Capitular y Colombina de Sevilla (Sign. 7-1-33).

${ }^{4}$ Para la polémica entablada entre Fernando de Herrera y el Prete Jacopín, vid. José María Asensio (1870) y Juan Montero (1987). Vid. también Bienvenido Morros (1998).

${ }^{5}$ Begoña López Bueno (1997: 192, n. 24) estima que las aportaciones de Herrera «fundamentan una teoría sobre el soneto no escasa en hallazgos expresivos para la caracterización estructural de tan cerrado paradigma».
} 
original; «en raras ocasiones menciona la fuente (o simplemente se refiere a un vago e indefinido «dicen algunos»), mientras que en las más la silencia» (1997: 57). Se trataría, en todo caso, «de una práctica generalizada entre los humanistas» $(1997: 58)^{6}$.

Volviendo al «discurso» sobre el soneto, es preciso indicar cómo, para Herrera, la claridad y la sencillez que requiere este género no han de ser llevadas al extremo de que se pierdan «los números i la dinidad conveniente». La dificultad del soneto deriva de «estar encerrado en un pequeño y perpetuo espacio», y es mayor que en los versos latinos, «porque en nuestra lengua, assí como en la toscana, demás de los pies, que más por naturaleza que por alguna regla es necesario guardar en los versos, concurre también esta dificultad de las rimas», y ciertamente «nuestros versos no están faltos de pies, porque se pueden componer muchos que contengan onze sílabas sin que en ellos se perciba algún sonido de versos o cualquiera otra diferencia de la prosa».

El verso endecasílabo, el metro central de la poética herreriana, ha de tener obviamente once sílabas. Pero no basta con esto. Hay que tener en cuenta también los «números» y los «pies», es decir, el ritmo y sus correspondientes pautas acentuales. En otro caso, las once sílabas no constituirían un auténtico verso, y no se diferenciarían en nada de la prosa. El soneto «consta de catorze versos endecasílabos i se divide en cuatro partes». Las dos primeras se llaman «en lengua italiana, del número de cuatro versos de que se compone, primero i segundo cuadernario, i cuartel en la nuestra». Las dos últimas partes, «de tres versos en que se cierra cada una, se apellidan primero i segundo ternario, o terceto».

En cuanto al «ritmo i consonancia», esto es, la rima, es igual en los dos cuarteles o cuartetos, mientras que los tercetos llevan «cadencias» diferentes. En el soneto, los endecasílabos no tienen por qué someterse siempre a la esticomitia. Por el contrario, se permite el encabalgamiento, «que cortar el verso en el soneto, como Quién me dixera, cuando en las pasadas / oras, no es vicio, sino virtud». En todo caso, «este rompimiento no á de ser contino, porque engendra fastidio la perpetua semejança».

Debemos a Francisco Petrarca el arte de los sonetos, porque él fue «el primero que los labró bien i levantó en la más alta cumbre de l' acabada hermosura i fuerça perfeta de la poesía», destacando también en este arte Iacobo Sannazaro y Pietro Bembo. En España, «aunque la poesía no es tan generalmente onrada i favorecida como en Italia», existen asimismo destacados sonetistas, sin que haya que remitirse «a la edad de Boscán, como piensan algunos», ya que el Marqués de Santillana es autor de algunos sonetos que son «dinos de veneración». Tras él vienen Juan Boscán 7 , Diego de Mendoza, Gutie-

\footnotetext{
${ }^{6}$ Sobre el concepto de la «imitación» en la poética renacentista, vid. Pego Puigbó (2003: 5-29).

${ }^{7}$ Cita Herrera a Juan Boscán a continuación de Diego de Mendoza y Gutierre de Cetina. Lo deja en último lugar, precisamente porque le dedica una especial atención. No obstante,
} 
rre de Cetina y, sobre todo, Garcilaso de la Vega, «príncipe de la poesía en nuestra lengua».

La canción es un poema lírico «nacido para alabanças i narraciones de cosas hechas, i deleites i alegrías i convites». Requiere este género «ingenio vivo i espiritoso, voluntad cuidadosa i trabajadora, juicio despierto y agudo, las vozes i oración polida, limpia, castigada, eficaz i numerosa». Acertadamente, relaciona Herrera los poemas líricos con las voces griegas $\omega_{1}^{\prime} \delta \eta \dot{~(c a n t o, ~}$

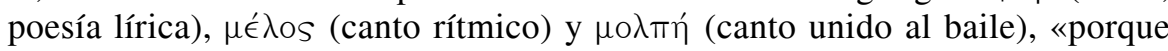
no se pronunciavan sin el canto i la lira». De ahí que Horacio llamara «Odas a sus libros, porque se cantavan».

Consta la canción de distintos «miembros, que se llaman estanças, cuyo número i modo de versos i rimas, junto con las vozes, que consuenan, puede colocar el poeta como le pareciere, i componer d'ellos la primera estança, siguiéndola sin variar en las siguientes». Reproduce Herrera las palabras de Pietro Bembo: en las canciones «se puede tomar cualquier número, tipo i rima de versos para componer la primera estrofa», pero «una vez escogidos, será necesario seguirlos en las otras con las mismas leyes que el poeta ha tomado libremente» (Bembo, 2011) ${ }^{8}$.

Tiene «tres partes principales: principio, narración, salida o fin». El fin, la última estancia «se llama conviato en toscano». Hace Herrera una mención muy escueta de las estancias o partes de la canción, afirmando que la última estancia se llama conviato en la lengua toscana. En realidad, se refiere al commeatus (permiso, licencia para salir) latino, o commiato italiano.

Contrasta la brevedad en la descripción herreriana de las canciones con la gran extensión que le dedica algún tratadista en lengua toscana, como Antonio Sebastiano Minturno, a quien precisamente Herrera cita en varias ocasiones. Indica Minturno (2009) que las estancias pueden ser continuadas o divididas. Estas últimas pueden ser, a su vez, simples y compuestas. Las simples constan de fronte y sirima; y las compuestas, de pies y versos. La cosa se complica aún más, puesto que tanto la fronte como la sirima pueden ser simples o compuestas. Además, si la fronte es simple, conviene que la sirima sea compuesta. A partir de aquí, nos sumerge Minturno en un piélago interminable de frontes simples y compuestas, sirimas simples y dobles, partes, números, sílabas, versos, pareados, tercetos, cuartetos, estancias, vueltas y revueltas (Torre, 2010). Es de agradecer la brevedad de Fernando de Herrera.

La elegía es una forma de poesía mélica, que, según Herrera, se llamó elegidia (plural de elegidion, pequeña elegía), porque se reunían las musas en

se ha querido ver en este hecho una prueba del «proceso de postergación cronológica al que es sometido el verso del barcelonés» (Lorenzo, 2013: 167) en la recepción de Boscán en las Anotaciones de Herrera.

${ }^{8}$ Vid. Isabel Paraíso (2012: 145). Considera esta autora las Prose della volgar lengua de Pietro Bembo como la primera Gramática del volgare italiano. Su teoría métrica, en cambio, sería breve y generalista, no pasando de constituir un documento meramente curioso. 
Lesbos en las celebraciones funerales y solían prorrumpir allí en lamentaciones. Tras exponer diversas hipótesis sobre su origen, termina reconociendo, con Horacio, «que no se sabe su autor». En cuanto a la etimología del término, cita, entre otras, la acertada teoría de Pomponio Gáurico, quien sostenía que el término proviene de é $\lambda \epsilon \gamma \in \hat{\epsilon} \alpha$. Y se nos dice que ha de ser «cándida, blanda, tierna, suave, delicada, tersa, clara», y además «noble, congoxosa en los afetos i que los mueva en toda parte; ni mui hinchada ni mui umilde; no oscura con esquisitas sentencias i fábulas mui buscadas; que tenga frequente comiseración, quexas, exclamaciones, apóstrofos, prosopopeyas, escursos o parébases». $\mathrm{Su}$ ornato deberá ser «más limpio i reluciente que peinado i compuesto curiosamente».

Los españoles, cuya lengua «es sin alguna comparación más grave i de mayor espíritu i manificencia que todas las que más se estiman de las vulgares», lograron «hermosear sus escritos variamente con flores y figuras», y mostrar en ellos no sólo «carne i sangre», sino también «nervios». Y no ha de reputarse como falta «tener el estilo levantado, como no sea túmido, que es cuando uno emprende grandes cosas i no las acaba». Ciertamente es difícil «dezir nueva i ornadamente las cosas comunes», de ahí la importancia de «hazer nuevo lo que no lo es».

Por su parte, los italianos imitaron a los latinos en los tercetos, «que son dichosamente traídos de la elegía». Y «tomaron por nombre tercia rima i cadena», esto es, tercetos encadenados. En esta forma estrófica, fue Dante «el primero por ventura de todos, porque ante d'él no está en memoria quién lo supiese».

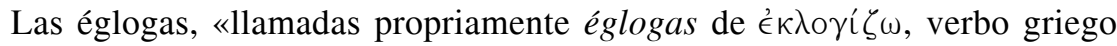
que en el lenguaje romano sinifica seligo, en el nuestro escojo, como versos escogidos i bien compuestos, son el más antiguo género de poesía». Aunque su temática es variada, «parece que es más antigua la amatoria». Como quiera que los griegos escribieron las églogas en hexámetros, «en lengua dórica, es razón que fueron dóricos los inventores d'esta poesía». Se llamó bucólico

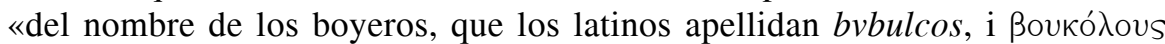
los griegos, que es el más aventajado género de pastores; porque, como escrive Elio Donato, tres son los géneros de pastores que tienen dinidad en las bucólicas: los bubulcos, los opiliones (dichos casi como oviliones), que son ovegeros, i últimos de todos los épolos, que son los cabrerizos». Los temas de las bucólicas son «las cosas i obras de los pastores, mayormente sus amores, pero simples i sin daño, no funestos con rabia de celos, no manchados con adulterios; competencias de rivales, pero sin muerte i sangre». Los pastores ofrecen a sus amadas dones que «tienen más estimación por la voluntad que por el precio, porque envían mançanas doradas o palomas cogidas del nido».

La dicción de las églogas es «simple, elegante»; los sentimientos, «afetuosos i suaves»; las palabras «saben al campo i a la rustiqueza de l'aldea, pero no sin gracia ni con profunda inorancia i vegez, porque se tiempla su rustici- 
dad con la pureza de las vozes proprias al estilo». Los más destacados autores son Virgilio y Garcilaso «i al contrario Batista Mantuano i Iuan del Enzina, infacetíssimos escritores de églogas». Entre los griegos, destaca Teócrito, y entre los latinos, Virgilio. «Desde éstos hasta la edad de Petrarca i Bocacio no uvo poetas bucólicos». Últimamente, «florecieron Sanazaro i Gerónimo Vida». En España, «sin alguna comparación, es príncipe Garci Lasso».

Tras las octavas reales de la Égloga III, indica Herrera que «sin duda alguna fue autor de las estanças o rimas otavas Iuan Bocaccio». Estos versos «se llaman del número d'ellos otava rima, i se responden alternadamente desde el primero hasta el sesto verso en las vozes postreras, que se terminan semejantemente; i los dos que restan, que perfecionan i acaban el sentido, i por esso se llaman la llave en toscano, tienen unas mesmas cadencias, diferentes de las primeras».

Luego explica que rima proviene del griego pîtuós, que corresponde al numerus latino. De este comentario a la Égloga III se deduce, según Emiliano Díez Echarri, que Fernando de Herrera «identifica la rima con el ritmo» (Díez Echarri, 1949: 105). Y es que Herrera «confunde en un solo concepto rima y ritmo, dándoles idéntica etimología» (Díez Echarri, 1949: 120). Es cierto: rima y ritmo tienen la misma etimología. No yerra en esto Fernando de Herrera. Pero es que, además, con el nombre de rima se designaba en el siglo XVI, en España, y no sólo en España, toda clase de composición poética. Por eso escribe Herrera que la rima es «una resonancia, dize el Trissino en su Poética, que resulta de cierta cantidad i calidad de sílabas puestas juntamente» ${ }^{9}$. En definitiva, «rima es número y consonancia».

Por rima entiende Herrera la rima consonante. De ahí que tenga como «vicio» el «assonante». En los versos «estuvo halagando las culebras / de las hermanas negras malpeinadas» (Égloga II, 945-946) es asonante la rima al mezzo «culebras/negras». Y anota Herrera: «el assonante, que responde a esta voz, i los que ái en esta égloga, puedes i deves, acabo i hago, campo i blanco, sangre i estambre, quiere $\mathrm{F}$ [rancisco] de Medina que sea en nuestra lengua figura assonancia». Sucede esto «cuando la sílaba, que suena para la consonancia, es poco diferente del'antecedente como avía de ser». Esta figura «sirve para escusar el vicio, i no para imitallo». En cualquier caso, «à de ser con tan poca diferencia, que casi engañe al oído». Garcilaso hace uso en otros lugares de la rima al mezzo. Así, por ejemplo, en el primer parlamento de Camila, en la Égloga II, 721-725: «Si desta tierra no è perdido el tino, / por aquí el corço vino, qu'à traído / después que fue herido, atrás el viento. / ¿Qué rezio movimiento en la corrida / lleva, de tal herida lastimado?». No distingue Herrera entre la rima al mezzo y la rima interna de los versos leoninos, y

\footnotetext{
9 «La rima es lo que los griegos llaman "rithmo" y los latinos "número"; por lo cual se puede decir que rima, ritmo y número son lo mismo. [...] es una resonancia que resulta de cierta cantidad y cualidad de sílabas, puestas juntas según una norma» (Trissino, 2014: 97).
} 
anota en relación con los citados versos: «los versos, que los antiguos llamaron leoninos, i no sabemos por qué, son viciosos en la poesía latina».

Garcilaso utiliza ampliamente el endecasílabo blanco. No le pasó desapercibido a Herrera este extremo, y así apunta a continuación de la Epístola: «Estos versos, que por no ligarse con alguna lei de números de semejante cadencia en el último asiento, se llaman sueltos en el vulgar italiano». El «defeto de la consonancia» debe ser compensado con un cuidadoso «ornamento». Estos versos «son invención de los poetas modernos, porque no se halla memoria dellos en los antiguos italianos». Siguiendo a Cintio Giraldo, considera como «inventor destos versos al Trissino, que escribió en ellos la Italia libertada» ${ }^{10}$.

En conexión con el «número», esto es, el ritmo, la musicalidad del verso, está su medida, a la que Fernando de Herrera dedica una particular atención. Y cuestión capital para el cómputo silábico es el contacto entre vocales, ya sea en el interior de la palabra, ya sea entre palabras contiguas ${ }^{11}$. Así, en el verso «iëndo m'alexando cada día» (Soneto III, 3), Herrera pone la crema o signo de la diéresis sobre la $e$ (iëndo), y anota: «Diéresis o división, porque no se atan en este verbo estas dos vocales primeras, i con ellas se va apartando el verso».

La diéresis o azeuxis «aparta», alarga, aleja el verso, haciendo de él un perfecto endecasílabo; pero es que, además, tiene un valor simbólico de alejamiento: «sinifica aquella disolución de letras el intento de Garci Lasso». En todo caso, apuntilla Herrera, «cuando no fuera natural división d'estos elementos, o no fuera hecho artificiosamente aquel desatamiento, lícito es distraer las vocales, pues vemos que Terencio hizo trisílabo uëro i cuadrisílabo ü̈rginem».

También utiliza Herrera el punto alto (') como signo de la azeuxis. En relación con el verso «de áspera corteza se cubrían» (Soneto XIII, 5), escribe en nota dé áspera, señalando con el punto sobre la $e$ que Garcilaso «deshizo» la sinalefa. «El mesmo Lasso, en el Soneto 16: Mas infición de àire en solo un día». Y pone otros ejemplos de versos propios, como «i la montañả àspera parece» $\mathrm{y}$ «Aquí nó ėntra quien no es desdichado». Para el verso «¿piensas qu'es otro el fuego qu'en Oėta...?» (Elegía I, 253), indica: «Aquí está desatado el diftongo de Oėta, que en nuestra lengua diremos Eta».

A propósito del verso «no quedarà ya tủ ảlmá entera» (Elegía I, 42), advierte: «Algunos, pareciéndoles que está falto este verso de Garci Lasso, no considerando la diéresis, lo an emendado, o dañado, d'esta suerte: no quedarà ya toda tu alma entera». Y añade: «Pero Garci Lasso, que conocía mejor los

${ }^{10}$ Según Isabel Paraíso (2010: 111), Giangiorgio Trissino «con sus obras Sophonisba e Italia liberata da' Goti consagró la utilización del verso suelto para obras extensas, buscando la naturalidad y reproducir la grandeza del hexámetro».

${ }^{11}$ Para William Ferguson (1981: 36), es llamativa «la escrupulosa atención que presta Herrera a los encuentros de vocales en palabras contiguas». 
números, se contentó con aquel modo; porque de más de sinificar assí la falta del'alma, que él pretendió mostrar, no es floxo número de verso, sino artificioso i no ageno de suavidad». Como oportunamente señalan los atentos editores Inoria Pepe y José María Reyes (2001: 577), se refiere Herrera a la enmienda propuesta por Francisco Sánchez el Brocense (1600: 17). Pero, a decir verdad, en este caso resulta difícil mantener el ritmo o «número» del endecasílabo, que exigiría esta lectura: no.que.da.rá.ya.tu.al.ma.en.té.ra. Si la primera dialefa o azeuxis (tu / alma) es aceptable, no lo es tanto la segunda (alma / entera).

Distinto es el caso de la lectura herreriana del Soneto XXIII:

En tanto que de rosa i açucena

se muestra la color en vuestro gesto,

i que vuestro mirar, ardiente, onesto,

enciende el coraçon i lo refrena...

El Brocense (1600: 8) había escrito así el último endecasílabo de este primer cuarteto: «con clara luz la tempestad serena». Seguía el texto de la edición princeps de los poemas de Garcilaso de la Vega, editados como Libro IV en las obras de Juan Boscán (1543: 198), si bien hace constar: «Otros leen Enciende el coraçón, y lo refrena» $(8 \text {, anotación } 26)^{12}$. Pero Fernando de Herrera prefiere esta última lectura, y anota: «Assí se á de leer, i d'esta suerte dice don Antonio Puertocarrero que lo tiene de su suegro. Porque, como anda impresso, más sirve de sustentamiento del cuartel que de prosecución del intento». Piensa que la otra lectura nos ofrece un verso ripioso, de relleno, que sólo sirve «de sustentamiento del cuartel», es decir, para completar el cuarteto.

La elección de Fernando de Herrera no es caprichosa. La mirada de la doncella es ardiente, por lo que enciende el corazón; y, a la vez, es honesta, por lo que lo refrena. Así, escribe Herrera: «usa aquí Garci Lasso de hermosíssima figura, regressión o reversión, dicha de los griegos epanodos [ÉTávodos, vuelta, recapitulación] i de nosotros rebuelta, cuando bolvemos a las palabras ya propuestas por causa de mostrar la diferencia». Es de lamentar que el hispanista Elias L. Rivers (1981), que no parece tener una especial simpatía por las Anotaciones en su edición crítica de las Obras de Garcilaso, desestime la feliz enmienda de Fernando de Herrera.

Otras enmiendas de las Anotaciones son igualmente oportunas y estimables. Así, el verso «y más me duele el no osar deziros» (Soneto XXXVII, 3, de la edición de Rivers) aparece en la edición de Fernando de Herrera como «i más me duele nunca osar deziros» (Soneto XXXII, 3). Según Rivers (1981:

\footnotetext{
${ }^{12}$ En la misma anotación 26 (81r-81v), escribe el Brocense: «Este florido soneto es sacado del Tasso». Cita también a Ausiàs March, y añade: «Entrambos lo podrían sacar de aquel florido epigrama, que anda entre las obras de Virgilio, cuyo título es Rosa, y el postrer dicho dize assi: Collige, virgo, rosas».
} 
162), con esta enmienda o variante Herrera habría evitado «el hiato difícil» de «no osar». Aunque, a decir verdad, no era tan «difícil» este hiato, dialefa o azeuxis, ya que en la conciencia lingüística del hablante español del primer tercio del siglo XVI estaba aún presente el recuerdo del antiguo non, lo cual impedía la sinalefa o zeuxis entre «no» y «osar». Estimable es también la enmienda al verso «do quiera que sauces de oy más se hallen» (Égloga III, 359), que aparece en las Anotaciones como «do quiera que d'oi más sauzes se hallen».

La sinéresis o zeuxis aparece marcada por una tilde de acento circunflejo $\left({ }^{\wedge}\right)$, o bien dos tildes $\left({ }^{\wedge}\right.$ ‘’’), que posiblemente sean un recurso alternativo del tipógrafo. Esto es lo que, por ejemplo, encontramos en el verso «Yo avîa jurado nunca más meterme» (Soneto VII, 9). Anota Herrera: «Este verbo es bisílabo por la sinéresis o contracción, que es juntamiento o encogimiento de dos sílabas en una, i d'esta suerte ai muchos versos en Garci Lasso».

En efecto, en los endecasílabos de Garcilaso es frecuentísima (Torre, 2012) la sinéresis, zeuxis o unión silábica de la vocal tónica $i$ con las vocales abiertas $a$ y $o$, como en «Hermosas ninfas qu'en el rîo metidas» (Soneto XI, 1). Se considera también sinéresis la unión silábica de las vocales cerradas $i$ y $u$, como en el verso «la claridad contempla, el ruîdo siente» (Canción IV, 98), al que anota Herrera: «Esta sinéresis o contración, que Diómedes llama episinalefa, es conjunción de dos sílabas en una, i es frequentíssima a Garci Lasso».

La zeuxis entre vocales de palabras contiguas, o sinalefa, también es tenida en cuenta por Herrera. Así, a propósito del Soneto XII, escribe: «En este soneto se hallan muchas sinalefas, que es el concurso de solas vocales, dicho propriamente en lengua latina elisión, o colisión, o concursión, i en la nuestra herimiento». Y, en relación con el verso «i si no lo fabrico i lo renuevo» (Elegía II, 163), indica que las vocales «suenan más dulcemente que las consonantes i assí hazen más blanda la oración i con más lenidad i no con tanto ruido i estruendo». Pero un exceso de vocales y el encuentro entre ellas harían que la oración fuera «llena demasiadamente i viciosa»: «Llámase el concurso o

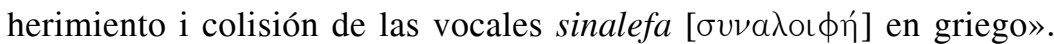

Hace uso Fernando de Herrera, como hemos tenido ocasión de ver, de los términos diéresis, sinéresis, sinalefa. Esta última se relaciona también con la elisión. Si tenemos en cuenta además los conceptos de hiato y diptongo, y en nuestros días la más reciente denominación de dialefa, como opuesta a la sinalefa, la terminología se complica y enmaraña, sobre todo cuando no existe una utilización unívoca de estos términos por parte de los distintos autores. De ahí la propuesta (Torre, 2011 y 2013), formulada en estos últimos años, de llamar sencillamente zeuxis a la unión silábica de dos o más vocales en contacto, y azeuxis a la separación de las mismas en sílabas diferentes, tanto en el interior de la palabra aislada como entre palabras contiguas. En cualquier caso, lo que persigue Herrera, con su peculiar notación de la diéresis o azeuxis (iëndo) y la sinéresis o zeuxis (avîa, rîo) en el interior de la palabra, así como 
de la dialefa, ausencia de sinalefa o azeuxis (montaña àspera, aquí no ëntra) entre palabras contiguas, es indicar claramente cuándo hay unión silábica o zeuxis $\left({ }^{\wedge}\right)$ y cuándo hay desunión o azeuxis (“ en la palabra aislada, ‘ entre palabras contiguas).

La preocupación de Fernando de Herrera por la división silábica de las palabras y de las frases, con vistas a una adecuada escansión del verso, reaparecerá tres siglos más tarde en los escritos de Eduardo Benot. En un primer momento, propone el polígrafo gaditano la colocación de dos puntos o crema para indicar la azeuxis: rïó, desafió; o bien una tilde como la del acento grave francés: riò, desafiò (Benot, 1853: xxiv). Posteriormente, a partir de 1865, prefiere hacer uso del llamado subpunto ${ }^{13}$ : rịó, desafió. En su monumental Prosodia castellana y versificación (1892) utiliza ya sistemáticamente, tanto en el verso como en el texto doctrinal, el subpunto como índice tipográfico ${ }^{14}$, lo cual constituye un verdadero tesoro para los estudios de prosodia y para la ciencia del verso.

Tampoco se le pasan por alto a Fernando de Herrera los juegos aliterativos como elementos ornamentales y genuina expresión del simbolismo fónico. Así, en el verso «de mi bien a mí mismo voi tomando» (Soneto XIX, 5), anota: «Suave es i agradable el verso que tiene anominación en las sílabas, que es lo que dizen otros aliteración». Cita a Petrarca, en el Soneto I: «di me medesmo meco mi vergogno», que tradujo Garcilaso en la Égloga I: «i de mí mismo yo me corro agora». Y añade: «A esta concinidad de tres aliteraciones llama Marciano Capela, en el Libro 5, metacismo; cuando la conjunción de la voz se colide muchas veces con este elemento $m$ ». En el verso «o a la que por el cielo congelado» (Canción I, 4), apunta: «Es landacismo, donde la $l$ suena muchas vezes». Y a propósito del verso «el humo sube al cielo, el son s'escucha» (Elegía II, 60), escribe: «Es sygmatismós, que ai tres $s$ en principio de 3 diciones» ${ }^{15}$.

Especialmente sensible es Fernando de Herrera al ritmo acentual. A propósito del verso «Cortaste '1 árbol con manos dañosas» (Soneto XXV, 3), advierte que «à de leerse haziendo assiento en el árbol». Es tan fuerte, en

13 «Un punto colocado debajo de una vocal indica que esta vocal no forma diptongo con la siguiente» (Benot, 1865: 4).

14 «Un punto bajo una vocal indica que esta vocal no se junta a la sílaba siguiente ni el diptongo ni en la sinalefa» (Benot, 2003: 5).

${ }^{15} \mathrm{Y}$ explica Herrera: «el lugar es de aquel maravilloso verso i lleno de celeridad, nec se iam capit unda, uolat vapor ater ad auras, donde Virgilio puso tres $U$ en principio de 3 diciones». Juan Francisco Alcina Rovira (1983: 349) indica que este verso virgiliano (Aen., VII, 466) aparece justamente citado por Giovanni Pontano (1943: 185), y que «una buena parte de las observaciones de Herrera sobre métrica giran en torno a la distribución de vocales y consonantes en la poesía de Garcilaso». El trabajo de Alcina, titulado «Herrera y Pontano: la métrica de las Anotaciones», está dedicado en su totalidad al estudio de las deudas textuales de Herrera con Pontano. 
efecto, el acento de la sílaba $4 .^{\text {a }}$ (ár-, de árbol) que todas las demás quedan debilitadas hasta llegar a la $10 .^{a}$ final. Así pues, podemos hacer la siguiente lectura: cor.tas.te’l.ár.bol.con.ma.nos.da.ñó.sas.

Aparecen otros endecasílabos en la obra poética de Garcilaso de la Vega con fuerte acentuación en las sílabas $4 .^{\mathrm{a}}$ y $10 .^{\mathrm{a}}$, y con intensidades y tonos más atenuados en las sílabas intermedias. Este tipo de endecasílabo ha sido tildado a veces de verso «desmayado», aunque también puede considerarse como una variedad del endecasílabo sáfico:

pienso remedios en mi fantasía (Soneto III, 6)
libre 'l lugar a la desconfiança (Soneto IV, 4)
en salvo d 'estos acontecimientos (Soneto XX, 6)
Después acá de lo que consentí (Soneto XXVII, 5)
a romper esto en que yo me metí (Soneto XXVII, 8)
mas es a tiempo que de mi baxeza Soneto XXVIII, 7)
un dulce amor, y de mi sentimiento (Soneto XXXI, 2)
me quexo a vos como si en la verdad (Canción II, 24)
un campo lleno de desconfiança (Canción IV, 89)
Algunos premios o agradecimientos (Elegía I, 92)
se contradizen en lo que profieren (Elegía II, 15)
Quál es el cuello que como en cadena (Égloga I, 131)
hinchen el aire de dulce armonía (Égloga II, 69)
al sueño ayudan con su movimiento (Égloga II, 76)
Tras esto luego se me presentava (Égloga II, 1122)
salir el humo de las caserías (Égloga II, 1871)

Todos estos versos han de leerse poniendo énfasis — haziendo assiento, según el sentir de Herrera- en la palabra portadora del acento correspondiente a la sílaba $4 .{ }^{a}$. No se trata en absoluto de versos defectuosos, flojos o desmayados, sino que, por el contrario, las dos cúspides acentuales de las sílabas $4 .^{\mathrm{a}}$ y $10{ }^{a}$, en contraste con la suave atenuación rítmica de las restantes sílabas, cumplen un oportuno papel de moderación y contrapunto en la serie versal. Más que de descuido o defecto, habría que hablar de exquisita labor de cincelado poético (Torre, 2012: 194). Herrera supo verlo, y oírlo, muy bien.

Preocupado por la perfección del verso endecasílabo, no es extraño que Fernando de Herrera encontrara dificultades para justificar la existencia de «endecasílabos» de diez o de doce sílabas. Así, en relación con el verso «adonde para siempre avrán d'estar» (Canción II, 12), escribe: «Los versos troncados, o mancos, que llama el toscano, i nosotros agudos, no se deven usar en soneto ni en canción». Y explica que «cuando los versos mudan la propria cantidad, que o son menores una sílaba o mayores otra, si no muestran con la novedad i alteración del número i composición algún espíritu i sinificación de lo que tratan, son dinos de reprehensión». Es decir: deben evitarse, en principio, los versos de una sílaba menos (agudos) o una sílaba más (esdrújulos).

Por lo que respecta a los esdrújulos, y a propósito del verso «verde texida, aquel valle atajávamos» (Égloga II, 210), escribe: «Quieren algunos que 
estos versos de 12 sílabas nascan de los endecasílabos, quitando de la última región el troqueo, como haga, i repuesto en su lugar el dátilo, hágase». Dicho de otro modo, tales versos de doce sílabas tienen alguna relación con los auténticos endecasílabos, y trata Herrera de explicarlo acudiendo a los principios de la métrica clásica. Y añade: «Otros entienden que sea invención sacada de los líricos asclepiadeos, como Maecenas atavis edite regibus, que es de 12 sílabas i esdrúxulas en el fin con dos sílabas graves, después de la 10, aguda o larga como nuestros esdrúxulos». Explica así su etimología: «Tomaron nombre de aquella ligera pronunciación que tienen con celeridad en el fin, llamándose versos esdrúxulos, porque sdrucciolare es en italiano aquel deslizar i huir de pies que haze el que passa por cima del ielo».

Considera, de acuerdo con el criterio general de la época, como sílabas «graves», o breves, las dos sílabas átonas (undécima y duodécima) que siguen a la tónica final (décima) del endecasílabo, «aguda o larga». Asimilar las sílabas tónicas a las largas de la métrica clásica, y las átonas a las breves, es un prejuicio que estuvo vigente hasta los años finales del siglo XIX, y que, en ocasiones, ha llegado hasta nuestros días, no sólo en la aclimatación de los pies métricos grecolatinos a las actuales cláusulas rítmicas, sino también en el cómputo de las terminaciones agudas y esdrújulas, otorgándosele a la tónica final de la terminación aguda el valor de dos tiempos silábicos, y a las dos postónicas de la terminación esdrújula el valor de un solo tiempo silábico (Torre, 1999: 55). En cualquier caso, es digna de admiración la prudencia de la que hace gala Fernando de Herrera al abordar este tema. Admite la existencia de versos agudos de diez sílabas y esdrújulos de doce junto a los canónicos versos llanos de once sílabas, que serían propiamente los versos endecasílabos. Para los agudos y esdrújulos, que implican «novedad i alteración del número», exige un especial «espíritu» y cuidado.

En lo que concierne al lenguaje tropológico y figurado, la «metáfora», o «traslación», juega un papel central en la poética de Fernando de Herrera. Aparece ya mencionada en las primeras anotaciones. En el verso «i a ver los passos por do m'á traído» (Soneto I, 2), advierte que «los passos» son «metáfora o traslación del caminante». Y, en relación con el verso «mas cuando del camino estó olvidado» (Soneto I, 5), indica que «prosigue en la metáfora, i es apódosis o redición, que aplica lo dicho».

En «mis lágrimas an sido derramadas / donde la sequedad i l'aspereza / dieron mal fruto d'ellas i mi suerte» (Soneto II, 9-11), considera la sequedad como «traslación de la agricultura», y añade que «de todos los ornamentos poéticos, el que más frecuentemente se usurpa i más parece por exemplo en la poesía es la traslación». A renglón seguido, da comienzo a una extensa disertación sobre la metáfora, distinguiendo inicialmente entre el significado recto, o propio, y el figurado, o tropológico: «Cada una de las cosas tiene su nombre, porque de otra suerte no podríamos hablar propriamente, aunque son más las cosas que se an de sinificar que las palabras i los proprios que las sinifican». 
Las palabras, como dice Aristóteles, son «proprias o agenas». Las proprias «se hallaron por necesidad, i son las que sinifican aquello en que primero tuvieron nombre». Las agenas nacieron «por ornato, i son las que se mudan de la propria sinificación en otra, a quien los griegos llamaron tropos de la mudança del entendimiento, i Aristóteles, del verbo $\mu \in T a \phi \epsilon ́ \rho \omega$, que es trasfiero, metáforas, i los latinos traslaciones». A este respecto, conviene recordar que tropo (тро́тоs, vuelta, giro, manera, cambio) significa efectivamente «mudança», y metáfora ( $\mu \in T a \phi o \rho a ́$, traslado) «traslación».

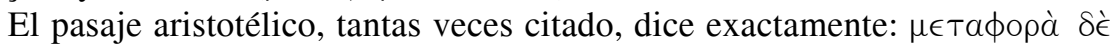

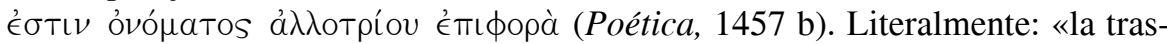

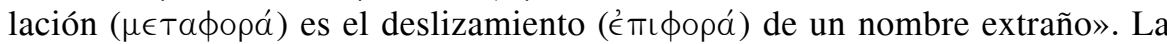
metáfora es, así pues, en el sentir aristotélico, un deslizamiento, un resbalón, un lapsus: hay una transposición de un nombre a una cosa distinta. Esta transposición puede ser, según Aristóteles, del género a la especie, de la especie al género, de la especie a la especie, o por una relación analógica.

Es la relación de analogía, o proporcionalidad, la que actualmente se considera como metáfora, mientras que las otras transposiciones suelen hoy reci-

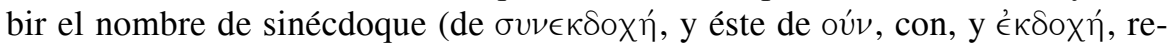
cogida, sucesión, interpretación) o metonimia (de $\mu \in T \omega \nu v \mu i ́ a$, empleo de un nombre por otro). Pero también hoy se habla, sencilla y genéricamente, de tropos o imágenes. Las excesivas distinciones forman parte más bien del ámbito erudito y académico que del crítico y teórico. En cualquier caso, Herrera no desconoce los términos sinécdoque y metonimia, como tendremos la ocasión de ver más adelante.

Sigue diciendo Herrera que «el primer uso d'estas vozes estrañas fue por necesidad, i después, viendo que hazía hermosa la oración, se valieron d'ella por gracia de ornato i deleite», y también «por metonimia, o antonomasia, o perífrasis, o ipérbole; i por las demás figuras con que se haze la oración más grave o más elegante» ${ }^{16}$. Y añade: «assí como no se deve hablar siempre proprio, no se á de hablar siempre figurado, porque á de aver modo en el uso, que es en estas cosas singular virtud». Por otra parte, «no todas las traslaciones que admiten los poetas tienen lugar en la prosa; i muchas de las que entran en la oración suelta no caben en el verso».

Y no debe confundirse la metáfora con la comparación: «es de notar que la traslación donde interviene esta parte, casi, o como, se llama semejança i no tras-

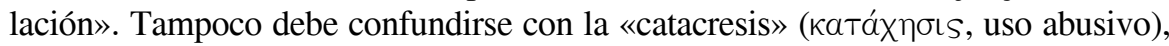
abusión o usurpación: «la abusión es donde falta de todo punto el nombre, i la metáfora donde uvo otro», y hay catacresis «cuando usurpamos i nos servimos con abuso de las vozes agenas por la semejança, como si fuessen proprias», de ahí que digamos «parricida al que mató al ermano, porque no se dize fratricida».

${ }^{16}$ Para Cristóbal Cuevas (1997: 165), el concepto de traslación «es central en la teoría del lenguaje poético del sevillano». 
Se relaciona con la metáfora la alegoría, «que es en latín diversiloquio o, como traduze Quintiliano, inversión, porque sinifica decir o predicar otra cosa; en nuestra lengua se podrá llamar permutación i trocamiento de las vozes al sentido», lo cual ocurre «cuando se dize una cosa i se entiende otra». En cambio, la metáfora es «traslación de una palabra, como decir el río de la elocuencia por la copia».

En los versos «mi alma os á cortado a su medida; / por ábito de l'alma misma os quiero» (Soneto V, 10-11), anota Herrera: «Es ábito disposición de lo perfeto a lo mejor. Esta disposición, si es conviniente a la naturaleza de la cosa, se dize buena, i si no, mala. En este lugar sinifica vestido, i es metáfora». Está aquí presente el juego metafórico del término hábito (latín habitus, francés habit, catalán hàbit) como costumbre y como vestido. El poeta desea revestirse de la amada: ha cortado, con el paño de ella, con la entretela de su ser, un traje a la medida de su propia alma. La imagen está tomada de Ausiàs March (1979: 394): Amor, Amor: un hàbit m'he tallat / de vostre drap, vestint-me l'espirit.

La misma imagen aparece también en el Soneto XXVII de Garcilaso: «Amor, amor, un ábito vestí, / el cual de vuestro paño fue cortado». A propósito de estos versos, advierte el Brocense (1600: 83, anotación 31): «Este soneto es traduzido de Ausias March, poeta lemosino». Los mismos versos fueron también vertidos al castellano por Jorge de Montemayor: «Amor, Amor: un hábito he cortado / de vuestro paño, el alma lo ha vestido» (March, 1990: 116) ${ }^{17}$. El mismo Herrera hace constar su fuente: «Este pensamiento es de Ausiàs, i pareció tan bien a don Diego de Mendoça que lo traduzió». No cita, sin embargo, la versión de Jorge de Montemayor ${ }^{18}$.

Como más arriba se indicó, Fernando de Herrera hace uso también de los términos metonimia y sinécdoque. A propósito del verso «la imagen amarilla del ermano» (Elegía I, 29), nos dice que «la metonimia» es «figura que los latinos llaman denominación o trasnominación, deduzida de $\mu \in T \mathrm{o \nu} \rho \mu a ́ \zeta \omega$, que es trasnombro». En realidad, toda transposición de nombres puede ser tenida por metáfora o metonimia. Así, en el verso «no recostado en urna 'l dulce frío» (Elegía I, 145), la mezcla cenestésica de los sentidos del gusto y del tacto en el sintagma «dulce frío», es considerada por Herrera como «metáfora del gusto al tocamiento», y especifica que «frío es sustantivo». La relación metonímica de causa a efecto aparece también con el nombre de metalepsis ( $\mu \in T a ́ \lambda \eta \psi \iota s$, cambio, permuta). Así, a propósito del verso «la sombra se veía / venir corriendo apriessa» (Égloga I, 414-415), apostilla: «Es metalesis, que del efeto se viene a la causa. Porque ya era noche se vía la sombra. I es epéntesis en el verbo veía, en lugar de vía».

\footnotetext{
${ }^{17}$ Según Enrique Nogueras Valdivieso y Lourdes Sánchez Rodrigo (2000: 373), «la versión de Jorge de Montemayor moderniza e italianiza el texto».

${ }^{18}$ Javier Lorenzo (2011: 481) hace notar que Fernando de Herrera «no menciona ni una sola vez a Montemayor en sus Anotaciones».
} 
Sobre el verso «Luego los aparejos ya de Marte» (Égloga II, 1354), se dice: «Metonimia figura, cuando el nombre de la causa se trasfiere al efeto». Y, en la anotación al verso «Italia tuvo tantas vezes puesto» (Égloga II, 1557), puede leerse: «Es metonimia cuando el nombre de la cosa sugeta se trasfiere a la que se le ayunta, como decir Italia por italianos. O cuando se entiende lo que contiene por lo contenido». Y se especifica: «es sinédoque, llamada latinamente conceción o inteleción, cuando se concibe en el ánimo más o menos, o otra cosa diferente de lo dicho; o cuando se pone la unidad en vez de la multitud o al contrario. Aquí es sinédoque de número por número, Italia por italianos».

Herrera hace uso también del término metagoge ( $\mu \in T a \gamma \omega \gamma \eta$, transporte, traslación). A propósito del verso «la fuente clara i pura, murmurando» (Égloga II, 1152), escribe: «Es metagoge, figura que los latinos apellidan tradución, cuando se refieren las cosa que pertenecen al sentido a las que carecen d'él, como reír el campo, alegrarse la tierra, etc.» Según el Diccionario de la Lengua Española, de la Real Academia, metagoge es «una especie de metáfora, que consiste en aplicar voces significativas de cualidades o propiedades del sentido a cosas inanimadas». Y se pone como ejemplo, precisamente, reírse el campo.

Entre las llamadas figuras de construcción, recoge Herrera la zeugma ( $\zeta \in \hat{v} \gamma \mu \alpha$, ligadura, junta). En los versos «Cuando me paro a contemplar mi estado / i a ver los passos por do m'á traído» (Soneto I, 1-2), señala a propósito de la forma verbal paro: «Es figura zeuma, que sinificará en español ligadura o ayuntamiento, cuando un verbo se llega comúnmente a muchas sentencias i conviene a todas con igual sinificado, como éste, que se refiere a contemplar i ver». Hace también mención del quiasmo ( $\chi\llcorner a \sigma \mu o ́ s$, incisión en forma de aspa), figura que consiste en cruzar las cuatro partes de una doble antítesis. En los versos «Tu templo i sus paredes é vestido / de mis mojadas ropas i adornado» (Soneto VII, 5-6), anota Herrera: «Puede ser esta figura xiasmós». Se corresponden el término «tercero [vestido] al primero [templo] i el cuarto [adornado] al segundo [paredes] $\gg^{19}$.

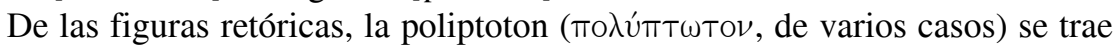
a colación a propósito de los versos «sé que m’acabo, i más é yo sentido / ver acabar conmigo mi cuidado. / Yo acabaré, que m'entregué sin arte / a quien sabrá perderme i acabarme» (Soneto I, 7-10). Hay poliptoton en el verbo acabar: «Este verbo, repetido cuatro vezes con variación de tiempo, sirve en lugar de la figura polítoton o tradución en nuestra lengua». Y especifica Herrera que esta figura «no como piensan algunos es aquí vicio, sino hermosísima

\footnotetext{
${ }^{19}$ Herrera toma la definición y adapta su ejemplo al propuesto por Julio César Escalígero (1561: 204). Vid. Bienvenido Morros (1997: 52). Parte Escalígero de los versos virgilianos Munera portantes, eborisque, aurique talenta, / Et sellam... (Aen., 11, 333-334). Se corresponde aquí el término primero (eboris) al cuarto (sellam), y el segundo (auri) al tercero (talenta).
} 
virtud de la oración» En cambio «no lo es por do, traído tres vezes» al comienzo del mismo soneto: «Cuando me paro a contemplar mi estado / i a ver los passos por do m'á traído / hallo, según por do anduve perdido... / a tanto mal no sé por dó é venido» (Soneto I, 1-3 y 5). En realidad, la repetición del sintagma por do no constituye una poliptoton, sino una simple iteración. No existen aquí distintos morfemas flexivos, como en el caso de acabo, acabar, acabaré. De ahí que Fernando de Herrera haga constar que esta repetición, «por do, traído tres vezes», no tiene la hermosura de la auténtica poliptoton.

Considera también Herrera como poliptoton o traducción la serie ofensa, ofensor, ofendido que aparece en los siguientes versos «Mas yo haré qu'aquesta ofensa cara / le cueste al ofensor, que ya estói sano, / libre, desesperado i ofendido» (Soneto XXXIII, 12-14). Escribe el crítico sevillano: «Estas tres voces variadas hacen una hermosa tradución de quien se á ya tratado en el Soneto I». Pero, a decir verdad, la figura retórica que entra aquí en juego no es la traducción o poliptoton, sino la derivación, esto es, la repetición de términos con igual lexema y distintos morfemas derivativos.

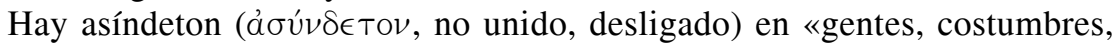
lenguas é passado» (Soneto III, 4). En este verso, anota Herrera, «usa Garci

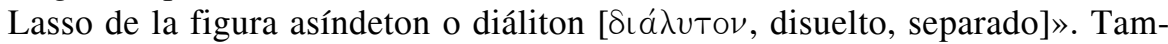
bién advierte el «asíndeton» en el verso «Corrientes aguas puras, cristalinas» (Égloga I, 239). En el Soneto XII, 2, «loco, imposible, vano, temeroso», se da asimismo «la dissolución, o assíndeton», además de «esta congerie de epí-

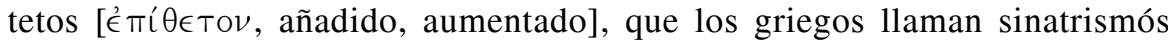

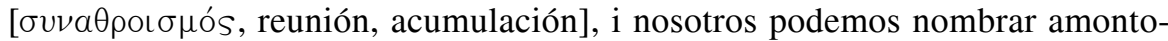
namiento de vozes». Existe aquí, así pues, abundancia de «epítetos, llamados por otro nombre apósitos, i en vulgar ayuntados». Y, en relación con los versos «donde no hallaréis sino mentiras, / vinos azedos, camareras feas, / varletes codiciosos, malas postas, / gran paga, poco argén, largo camino» (Epístola, 73-76), escribe Herrera: «Sinatrismós, acervo, congerie i asíndeton».

Otras figuras retóricas de amplificación y repetición son la expolición (expolitio, pulimento, amplificación) y la hendíadis ( te dos). En los versos «Yo, que desde la noche a la mañana, / i del un sol al otro» (Égloga II, 176-177), existe «espolición, i espergesia, que es declaración de la sentencia, cuando se esplica una mesma cosa trocando las sentencias». En el verso «la caça a cuestas, i la red cargando» (Égloga II, 232), «la red de la caça» es «figura endíadis, cuando el sustantivo por causa del verso se desata en el ayuntado o agetivo, o se contraen dos sustantivos en uno». Y añade Herrera: «Escalígero llama palilogia [ $\pi \alpha \lambda \iota \lambda \lambda \lambda_{0} \gamma^{\prime} \alpha$, repetición] a esta figura». El ejemplo propuesto por Escalígero, indica Herrera, es molemque et montes, tomado de Virgilio (Aen., 1, 65): Hoc metuens: molemque et montes insuper altos.

Aparecen también en las Anotaciones las figuras llamadas anadiplosis

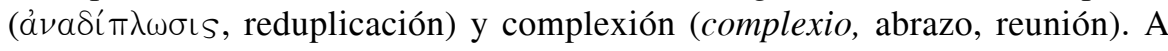


propósito de los versos «tan sólo, que aun de vos me guardo en esto. / En esto estói i estar é siempre puesto» (Soneto V, 4-5), en los que se repite en esto, anota Herrera: «La repetición al fin i al principio d'estos dos versos se llama anadiplosis poética o redoblamiento». Y, con respecto al verbo estaba en «Estava yo a mirar i, peleando / en mi defensa, mi razón estava» (Canción IV, 41), escribe: «Este uerbo al principio i al fin d'estos dos versos, que haze círculo en ellos, es figura simploce o complexión en latín, i en nuestra lengua repetición del verbo en principio i fin».

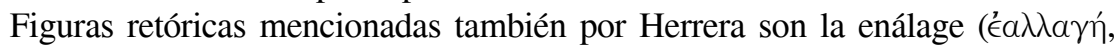

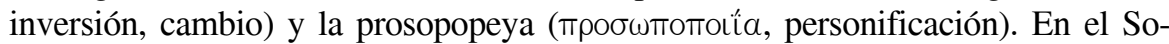
neto $\mathrm{XV}, 1$, «Si quexas i lamentos pueden tanto», la sustitución de pudieron por pueden «es enálage del tiempo». En la Elegía II, 27, «siempre à llevado i lleva Garci Lasso», habla Garcilaso, pero aparece en tercera persona: es «enálage de la tercera persona por la primera». Y, a propósito del Soneto $\mathrm{X}, 1-2, « \mathrm{O}$ dulces prendas por mi mal halladas, / dulces y alegres cuando Dios quería», indica el comentarista: «sírvese aquí de la figura prosopopeya, que los Latinos llaman conformación, i en nuestra lengua podrá tener por nombre fingimiento o hechura de persona».

Entre las figuras de dicción, se hace referencia a las siguientes: epéntesis

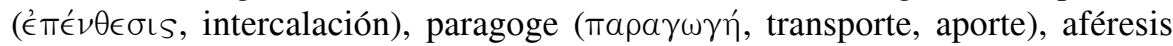

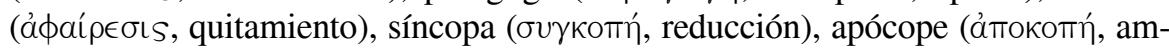

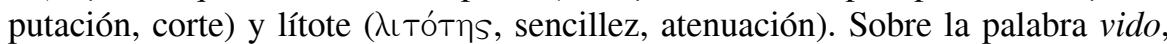
en el verso «Mas desque vido bien que, corrompiendo» (Elegía I, 226), se anota: «Epéntesis, que es interposición de una letra o sílaba en medio de la dición», ya que aparece vido por vio, que es la forma considerada por el comentarista como de uso normal ${ }^{20}$. En la palabra veloce de «qu'el veloce correr del agua enfrena» (Elegía II, 189), hay «paragoge o adición al fin, por veloz». En «secutando el efeto de su assunto» (Égloga II, 253), hay «aféresis o detración de una letra o sílaba en el principio de la dición, porque devía decir essecutando. En nuestra lengua se dirá (si se sufre) quitamiento». En el verso «abraçád de mi parte, si pudierdes» (Epístola, 82), aparece pudierdes por pudiéredes, y se anota: «en este verbo ai figura síncopa, que es cortamiento i detración de una letra i sílaba en medio de la voz». También en el verso «él solo con despierta vigilança» (Égloga II, 1234) anota Herrera: «Síncopa», ya que aparece vigilança por vigilancia. En el verso «antes d'aqueste al val de la hortiga» (Égloga II, 854), anota: «Apócope o cortamiento», ya que aparece val por valle. En relación con los versos «No soi, pues, bien mirado, / tan disforme ni feo» (Égloga I, 175-176), escribe: «Es figura litote, cuando se dize menos i se entiende más; porque quiere parecer mui hermoso, pero huyó de la jatancia».

\footnotetext{
${ }^{20}$ En el devenir diacrónico, vido precede a vio, por lo que más bien habría que considerar la pérdida de la $d$ en esta última forma verbal como un caso de síncopa. Cfr. Ramón Menéndez Pidal (1994: 318): «vīdit vido (hoy vulgar), vío (en los textos antiguos consonante de río), moderno vió».
} 
Es sabido que Fernando de Herrera se había propuesto la redacción de una completa Poética, que no sabemos si se llegó a escribir, pero que, en todo caso, no ha llegado hasta nosotros. En efecto, en el comentario a la Canción I, cuando se refiere a los poetas «vulgares» en relación con los griegos y latinos, declara que no se extiende demasiado en este tema «por aver de escrevir dellos, si diere espacio la vida, i no fueren contrarias las ocasiones, en los libros de la poética». Ningún otro dato tenemos sobre estos «libros de la poética». No obstante, las numerosísimas referencias que en sus Anotaciones hace a las cuestiones métricas y al lenguaje tropológico y figurado, y que he tratado de reunir, resumir y sistematizar aquí en sus rasgos fundamentales, nos revelan sin duda alguna a un profundo conocedor de las teorías poéticas clásicas y renacentistas, y también a un excelente poeta, que proyecta sobre una obra ajena sus propias ideas, con la generosidad, la dedicación y la perspicacia de un consumado crítico literario.

No comparto el adverso juicio de Emiliano Díez Echarri (1949: 105), para quien Herrera no sería precisamente un Góngora o un Lope en lo que concierne a la sonoridad y a la cadencia métrica: «Hora es ya de situar a este poeta — todo rimbombancias i oquedades- en el lugar que le corresponde». Según Díez Echarri, sólo en el soneto de la página 52 de las Anotaciones, ofrecido a la honra de Garcilaso, podríamos encontrar hasta cinco versos «que a duras penas tolera el oído medianamente formado»:

Mvsa, esparze purpúreas, frescas flores (v. 1)
Arda la rota aljava i passadores (v. 5)
la mirra i casia, i cuanto el encubierto (v. 6)
yaze entre verdes hojas d'amaranto (v. 11)
venere 'l alto i noble i tierno canto (v 14)

Pero la verdad es que ningún oído, no ya medianamente, sino exquisitamente formado, encontraría dureza alguna en estos versos, en especial el undécimo, «yaze entre verdes hojas d'amaranto», en el que a la melodía de una delicada secuencia de vocales se añade una perfecta orquestación consonántica. Cierto es que, en el esplendor de los Siglos de Oro - Lope de Vega, Luis de Góngora, Francisco de Quevedo_-, pueden tal vez quedar ensombrecidos los brillantes versos de Fernando de Herrera. En todo caso, el objeto de estas páginas no era el estudio del Herrera poeta, sino del Herrera teórico y crítico literario $^{21}$. Y, a este respecto, sigue teniendo plena vigencia y queda corroborada la penetrante visión de Marcelino Menéndez Pelayo, para quien las Anotaciones constituyen un verdadero curso de teoría literaria. Su autor se nos revela, efectivamente, como un consumado idólatra de las formas y como un extraordinario crítico literario: el primero de nuestros críticos del siglo XVI.

${ }^{21}$ En la trayectoria poética de Fernando de Herrera, podría también rastrearse la estructura de sus bases teóricas, ya que, como apunta Violeta Montori de Gutiérrez (1977: 44), «sus versos ilustran lo que expone teóricamente en sus Comentarios». 


\section{BIBLIOGRAFÍA CITADA}

Alcina Rovira, Juan Francisco (1983). «Herrera y Pontano: la métrica en las Anotaciones», Nueva Revista de Filología Hispánica. XXXII, 2, pp. 340-354.

Almeida, José (1976). La crítica literaria de Fernando de Herrera. Madrid: Gredos.

Asencio, José María (1870). Fernando de Herrera. Controversia sobre sus «Anotaciones» a las obras de Garcilaso de la Vega. Sevilla: Sociedad de Bibliófilos Andaluces.

Badía Fumaz, Rocío (2013). «Aspectos de la creación poética en las Anotaciones a la poesía de Garcilaso de Fernando de Herrera», Tonos digital. Revista electrónica de estudios filológicos. 2, 18, s.p.

Beach, Robert Mills (1908). Was Fernando de Herrera a Greek Scholar? Filadelfia: Universidad de Pensilvania.

Bembo, Pietro (2011). Prosas de la lengua vulgar. Oriol Miró Martín (ed. y trad.). Madrid: Cátedra.

Benot, Eduardo (1853). Nuevo método del Dr. Ollendorf para aprender a leer, hablar y escribir un idioma cualquiera. Adaptado al italiano. Cádiz: Revista Médica.

Benot, Eduardo (1865). Ollendorf reformado. Gramática inglesa, y método para aprenderla. Cuarta edición corregida nuevamente. Cádiz: Verdugo Morillas y Compañía.

Benot, Eduardo (2003). Prosodia castellana y versificación. Madrid: Juan Muñoz Sánchez. Esteban Torre (ed. facsímil). Anejo I de Rhythmica. Revista española de métrica comparada.

Boscán, Juan (1543). Las obras de Boscán y algunas de Garcilasso de la Vega. Barcelona: Carles Amorós.

Brown, Gary Joseph (1975). «Fernando de Herrera and Lorenzo de'Medici: The Sonnet as Epigram», Romanische Forschungen. LXXXVII, pp. 226-238.

Coster, Adolphe (1908). Fernando de Herrera (El Divino), 1534-1597. París: Champion.

Cuevas, Cristóbal (1997). «Teoría del lenguaje poético en las Anotaciones de Fernando de Herrera», en Begoña López Bueno (ed.), Las «Anotaciones» de Fernando de Herrera. Doce estudios. Sevilla: Universidad, pp. 157-172.

Díez Echarri, Emiliano (1949). Teorías métricas del Siglo de Oro. Apuntes para la historia del verso español. Madrid: CSIC.

Escalígero, Julio César (1561). Poetices libri septem. Lyon: Antoine Vincent.

Estévez Molinero, Ángel (1997). «Los descuidos de Garcilaso en la perspectiva crítica de Herrera (con algunas notas sobre las "necedades" en las Anotaciones», en Begoña López Bueno (ed.), Las «Anotaciones» de Fernando de Herrera. Doce estudios. Sevilla: Universidad, pp. 135-156.

Gallego Morell, Antonio (ed.) (1972). Garcilaso de la Vega y sus Comentaristas. Obras completas del poeta acompañadas de los textos integros de los comentarios de El Brocense, Fernando de Herrera, Tamayo de Vargas y Azara. 2. ${ }^{\text {a }}$ ed. revisada y adicionada. Madrid: Gredos.

Gallego Morell, Antonio (ed.) (1973). Obras de Garcilaso de la Vega con anotaciones de Fernando de Herrera. Madrid: CSIC.

Guevara, Pedro de (1586). Breve y sumaria declaración de la Arte general. Madrid: Pedro Madrigal.

Herrera, Fernando de (1580). Obras de Garci Lasso con anotaciones. Sevilla: Alonso de la Barrera.

Lázaro Carreter, Fernando (1980). «Dos notas sobre la poética del soneto en los Comentarios de Herrera, en Homenaje a F. Sánchez Castañar, Anales de Literatura Hispanoamericana. VIII, pp. 315-321.

López Bueno, Begoña (1997). «Las Anotaciones y los géneros literarios», en Begoña López Bueno (ed.), Las «Anotaciones» de Fernando de Herrera. Doce estudios. Sevilla: Universidad, pp. 183-199 
Lorenzo, Javier (2011). «Sobre un silencio de Herrera: Jorge de Montemayor y el problema de la modernidad en las Anotaciones», eHumanista. 17, pp. 478-495.

Luján, Ángel Luis (2000). «Las Anotaciones de Herrera y las formas estilísticas de la tradición hermogeneana», Hispanic Review. 68, pp. 359-380.

Macrì, Oreste (1972). Fernando de Herrera. Madrid: Gredos.

March, Ausiàs (1979). Obra poética completa, I. Ed. bilingüe de Rafael Ferreres. Madrid: Castalia.

March, Ausiàs (1990). Poesías, traducidas por Jorge de Montemayor. Martín de Riquer (ed. e intr.). Barcelona: Planeta.

Medici, Lorenzo de' (1554). Poesie volgari nuovamente stampate. Col commento del medesimo sopra alcuni de' suoi sonetti. Venecia: Aldo.

Medici, Lorenzo de' (1991). Comento de' miei sonetti. Tiziano Zanato (ed.). Florencia: Leo S. Olschki.

Menéndez Pelayo, Marcelino (1974). Historia de las ideas estéticas en España. 4. ${ }^{\text {a }}$ ed. Madrid: CSIC.

Menéndez Pidal, Ramón (1994). Manual de gramática histórica española. 22. ${ }^{a}$ ed. Madrid: Espasa Calpe.

Minturno, Antonio Sebastiano (2009). Arte poética. María del Carmen Bobes Naves (ed. y trad.). Madrid: Arco / Libros.

Montero, Juan (1987). La controversia sobre las «Anotaciones» herrerianas. Sevilla: Ayuntamiento / Alfar.

Montero, Juan (1997). «Las Anotaciones, del texto al lector», en Begoña López Bueno (ed.), Las «Anotaciones» de Fernando de Herrera. Doce estudios. Sevilla: Universidad, pp. 91-105.

Montero, Juan (ed.) (1998). Obras de Garci Lasso de la Vega con anotaciones de Fernando de Herrera. Ed. facsímil con un «Estudio biobibliográfico». Sevilla: Universidades de Córdoba, Huelva y Sevilla / Grupo PASO.

Montori de Gutiérrez, Violeta (1977). Ideas estéticas y poesía de Fernando de Herrera. Miami: Ediciones Universal.

Morros, Bienvenido (1997). «Las fuentes y su uso en las Anotaciones a Garcilaso», en Begoña López Bueno (ed.), Las «Anotaciones» de Fernando de Herrera. Doce estudios. Sevilla: Universidad, pp. 37-89.

Morros, Bienvenido (1998). Las polémicas literarias en la España del siglo XVI: A propósito de Fernando de Herrera y Garcilaso de la Vega. Barcelona: Quaderns Crema.

Nogueras Valdivieso, Enrique y Lourdes Sánchez Rodrigo (2000). «Ausiàs March y Jorge de Montemayor: traducción e interpretación», Annexes des Cahiers de linguistique hispanique médiévale. 14, 14, pp. 357-374.

Núñez Rivera, J. Valentín (1997). «Garcilaso según Herrera. Aspectos de crítica textual en las Anotaciones», en Begoña López Bueno (ed.), Las «Anotaciones» de Fernando de Herrera. Doce estudios. Sevilla: Universidad, pp. 107-134.

Paraíso, Isabel (2010). «Giangiorgio Trissino: innovador, poeta y máximo teórico de la métrica italiana renacentista». Rhythmica. Revista española de métrica comparada. VIII, 8, pp. 111-141.

Paraíso, Isabel (2012). «Las teorías métricas de Pietro Bembo en las Prose nelle quali si ragiona della volgar lingua», Rhythmica. Revista española de métrica comparada. X, 10, pp. 133-155.

Pego Puigbó, Armando (2003). «Hipertextualidad e imitación (A propósito de los «espíritus de amor» en Garcilaso», Revista de Literatura. 65, 129, pp. 5-29.

Pepe, Inoria y José María Reyes (ed.) (2001). Fernando de Herrera. Anotaciones a la poesía de Garcilaso. Madrid: Cátedra.

Piñero Ramírez, Pedro (2002). «Fernando de Herrera, Anotaciones a la poesía de Garcilaso», Minerva Baetica. XXX, pp. 305-313. 
Pontano, Giovanni (1943). I dialoghi. Carmelo Previtere (ed.). Florencia: Sansoni.

Pring-Mill, Robert (1967). «Escalígero y Herrera: citas y plagios de los Poetices Libri Septem en las Anotaciones», en Actas del Segundo Congreso Internacional de Hispanistas. Nimega, pp. 489-498.

Rivers, Elias L. (ed.) (1981). Garcilaso de la Vega. Obras completas con comentarios. Madrid: Castalia.

Sánchez [de las Brozas], Francisco (1600). Obras del excelente poeta Garci Lasso de la Vega. Con anotaciones y emiendas. Madrid: Luis Sánchez.

Sánchez Valdés de la Plata, Juan (1598). Coronica y historia general del hombre. Madrid: Luis Sánchez.

Torre, Esteban (1984). Sobre lengua y literatura en el pensamiento científico español de la segunda mitad del siglo XVI. Sevilla: Universidad.

Torre, Esteban (1999). El ritmo del verso. Murcia: Universidad.

Torre, Esteban (2010). «La métrica de Minturno», Rhythmica. Revista española de métrica comparada. VIII, 8, pp. 191-217.

Torre, Esteban (2011). «Zeuxis y azeuxis en la configuración silábica», Rhythmica. Revista española de métrica comparada. IX, 9, pp. 183-199.

Torre, Esteban (2012). «La perfección de algunos endecasílabos imperfectos de Garcilaso de la Vega», Rhythmica. Revista española de métrica comparada. X, 10, pp. 187-204.

Torre, Esteban (2013). «Zeuxis y azeuxis: más sobre vocales en contacto», Rhythmica. Revista española de métrica comparada. XI, 11, pp. 187-205.

Trissino, Giovan Giorgio (2014). La Poética. Isabel Paraíso (ed. y trad.). Madrid: Arco / Libros.

Vázquez Medel, Manuel Ángel (1983). Poesía y poética de Fernando de Herrera. Madrid: Narcea.

Vilanova, Antonio (1953). «Preceptistas españoles de los siglos XVI y XVII», en Guillermo Díaz Plaja (ed.), Historia general de las literaturas hispánicas, III. Barcelona: Barna, pp. 565-692.

Fecha de recepción: 24 de septiembre de 2014.

Fecha de aceptación: 6 de febrero de 2015. 